\title{
Ernest J. Zarra III (2019). Generación Z. La generación con derechos. Cómo educar para llegar a sus mentes y a sus corazones. Madrid: Narcea (Col.: Educación Hoy Estudios). 126 págs. ISBN: 978-84-277- 2653-6. ePdf: 978-84-277-2654-3. ePub: 978-84-277-2655-0
}

\author{
María Pilar Moragón Arias ${ }^{1}$ \\ ${ }^{1}$ Universidad de Vigo. mariapilarmoragon@uvigo.es
}

Recibido: $6 / 10 / 2020$

Aceptado: $26 / 10 / 2020$

Copyright (C)

Facultad de CC. de la Educación y Deporte.

Universidad de Vigo

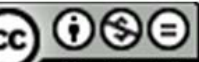

Dirección de contacto:

María Pilar Moragón Arias

Facultade de Ciencias da Educación e do Deporte

Campus A Xunqueira, s/n

36005 Pontevedra
Siguiendo la "moda" de las etiquetas generacionales, y en un tiempo de rápidos y constantes cambios, a veces casi abismales, este libro del profesor y formador de profesores estadounidense Ernest J. Zarra III trata de ahondar en los problemas de la última -por el momento-, de las generaciones definida: la llamada Generación Z. Es esta una generación enteramente tecnológica, de hecho la primera que no atesora recuerdos de una época anterior a lo digital, con la trascendencia que esto tiene, entre otros, en el campo de la enseñanza-aprendizaje. A la adicción a los dispositivos tecnológicos, que marcan sus ritmos de su vida, se unen unas características singulares, que la convierten, según el autor, en una generación "blanda", que se deja llevar por sus emociones, las cuales monopolizan buena parte de su vida y les lleva a creer que mediante ellas se puede acceder al conocimiento y a la verdad, determinado en gran medida su modo de actuar.

El autor considera además que estas características se ven potenciadas por una suerte de transformación gradual del "cableado" mental subsiguiente a la inmersión en el uso cotidiano de estas tecnologías, que propicia además la reducción de los lapsos de atención o las dificultades en el procesamiento de datos. A ello se añade la conciencia de un profundo sentido de sus derechos que determina su comportamiento y sus actitudes en el ámbito escolar y en la sociedad, lo que obligará a un replanteamiento general y necesario del proceso educativo.

A lo largo de las páginas del libro, el autor trata, a partir de sus propias experiencias y de las interrelaciones e interacciones con colegas de distintos niveles educativos, de ayudar a comprender las singularidades de esta generación que están marcando el devenir de la enseñanza y el aprendizaje en la actualidad. Para intentar evitar la incomprensión por parte de los docentes, la falta de ubicación y también, por qué no decirlo, la frustración ante una evidente ruptura generacional, incluso entre docentes jóvenes, el autor propone comprender y entender para poder actuar ante una generación distraída y dispersa, incapaz de sustraerse a sus "dispositivos" (que sustituyen muchas veces al "osito de peluche" en el imaginario cotidiano de los niños y niñas). El qué se puede y qué se debe hacer para tener éxito en la intervención pedagógica por parte del docente, una demanda a veces angustiosa ante las múltiples 
dificultades que se plantean en el día a día del aula, va paralelo al deseo de lograr el éxito a toda costa que tiene esta generación, y que es un trasunto del éxito instantáneo, fugaz y etéreo que pueden proporcionar las redes sociales.

Si ha cambiado, y nadie lo duda ya, el modo de aprender a través de la infoxicación que caracteriza a la sociedad contemporánea, tiene que cambiar también el modo de estar en el aula, de relacionarse, de comprender o de empatizar con una generación que no es ni mejor o peor que las anteriores (la X, los millenials...) sino distinta y también distante.

A través de los distintos capítulos Zarra reflexiona sobre las características intelectuales de esta generación, sobre cómo debe cambiar el rol de los docentes ante las peculiaridades, las necesidades, las aspiraciones de éxito y la visión de futuro de estos jóvenes, con una serie de estrategias que permitan "conectar" al docente con ellos y ellas, para lo cual se precisa un replanteamiento de la formación y de la función docente. Por ello deben conocerse las expectativas de esta generación $Z$, algunos de cuyos miembros están ya en la Universidad y a punto de entrar o dentro ya del mundo laboral, lo cual los coloca de forma dura, radical y, a veces brutal, ante la realidad del mercado. Precisamente, el último capítulo orienta sobre cómo tener éxito ante este grupo que protagoniza para bien o para mal buena parte de nuestra contemporaniedad, comprendiendo cómo aprenden, qué uso dan a las redes sociales y a las tecnologías para explotarlas con un beneficio mutuo, para poder gestionar de forma exitosa el aula. Se trata de que los maestros se aprovechen de la afinidad con la tecnología que tienen sus alumnos y alumnas: valorar las posibilidades de acceso a la información de forma inmediata como elemento muy motivador, proyectar y desarrollar actividades para la colaboración on line, potenciar lo visual en el aula, pero sin olvidar el desarrollo del pensamiento crítico y de la resolución de problemas, centrándose en una sola $\mathrm{o}$ en muy pocas tareas que tengan profundidad y complejidad, para evitar caer en lo instantáneo y en lo fugaz. A este respecto, son reveladores los diez consejos que el autor da para ayudar a los profesores entre las páginas 73 y 82 .

La reflexión final, "marcar la diferencia para ser un profesor diferente", sintetiza bien el espíritu del libro, que quizás adolezca de un excesivo enfoque en la realidad estadounidense, pero de la que sin duda se puede aprender en este planeta interconectado y globalizado. En suma, el libro es una proyección en la educación del clásico "adaptarse o morir", en este mundo vertiginoso que nos ha tocado vivir. 